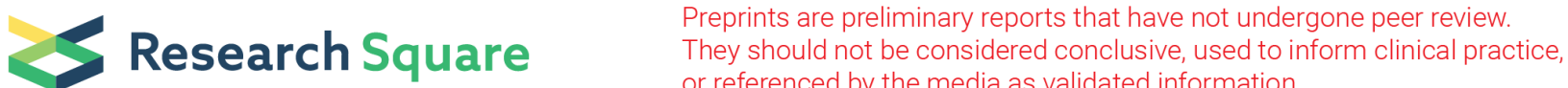

\section{Genetic Analysis of Cadmium Tolerance And Exploring Its Inheritance Nature In Bread Wheat}

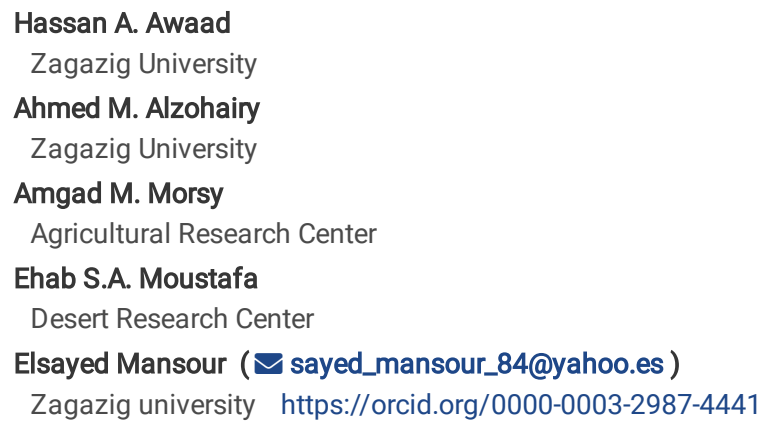

Hassan A. Awaad

Zagazig University

Ahmed M. Alzohairy

Zagazig University

Amgad M. Morsy

Agricultural Research Center

Ehab S.A. Moustafa

Desert Research Center

Elsayed Mansour ( $\square$ sayed_mansour_84@yahoo.es )

Zagazig university https://orcid.org/0000-0003-2987-4441

\section{Research Article}

Keywords: cadmium, RAPD, ISSR, heterosis, heritability, prediction, sensitivity index

Posted Date: May 11th, 2021

DOI: https://doi.org/10.21203/rs.3.rs-417444/v1

License: (c) (1) This work is licensed under a Creative Commons Attribution 4.0 International License. Read Full License 


\section{Abstract}

Cadmium (Cd) is a nonessential and extremely toxic element that destructively impacts agricultural production. Accordingly, developing tolerant-Cd as well as low-grain Cd genotypes is considered a promising approach to cope with the pollution problem. The current study aimed at understanding inheritance nature of $\mathrm{Cd}$ tolerance and detect $\mathrm{Cd}$-tolerant and low-grain $\mathrm{Cd}$ genotypes in bread wheat. Six parents were selected based on their Cd tolerance and were genotyped using triple-RAPD and ISSR markers to investigate their genetic diversity. The selected parents were crossed and the realized $\mathrm{F}_{1 \mathrm{~s}}$ were selfed to produce $\mathrm{F}_{2}$ populations and were backcrossed with their own parents to produce $\mathrm{BC}_{1}$ and $\mathrm{BC}_{2}$ populations. Six populations for each cross comprised $\mathrm{P}_{1}, \mathrm{P}_{2}, \mathrm{~F}_{1}, \mathrm{~F}_{2}, \mathrm{BC}_{1}$ and $\mathrm{BC}_{2}$ were evaluated in two adjacent experiments under non-Cd stressed and $\mathrm{Cd}$-stressed conditions. Significant positive relative and standard heterosis were detected for flag leaf area, leaf chlorophyll content, proline content, Cd concentration and grain yield/plant under Cd-stressed condition. Dominance gene effect was more pronounced in controlling the evaluated traits in most cases. F values coupled with $\mathrm{F} / \sqrt{ } \mathrm{H} \times \mathrm{D}$ ratio were positive for Cd concentration and Cd sensitivity index in the three crosses under both conditions. Heritability estimates from offspring regression were high ( $<50 \%)$ for flag leaf area, leaf chlorophyll content, proline content, $\mathrm{Cd}$ concentration while, moderately low for grain yield/plant and Cd sensitivity index. Prediction results revealed to high transgressive segregates and exceeding $F_{1}$ with best-inbred line ( $P$ max) that have all favorable alleles were obtained from 3rd cross for flag leaf area, low $C d$ concentration and Cd sensitivity index under Cd-stressed conditions.

\section{Introduction}

Heavy metals are one of the main obstacles that seriously threaten food safety (Konate et al., 2017; Rizvi et al., 2020). Cadmium (Cd) is one of the most prevalent toxic heavy metals that negatively impact plant growth and development (Tolcin, 2009; Shafiq et al., 2019). Cd is usually released from industrial activities as plastic manufacturing, refining and mining (Dong et al., 2019). Furthermore, increasing consumption of phosphate fertilizers and irrigation using wastewater leads to widespread Cd pollution in farmland (Zhang et al., 2015; Zaid et al., 2018). Cd causes numerous physiological disorders in lipid and protein synthesis, cell membrane and nutrient metabolism (Chugh and Sawhney 1999; Lesser, 2006). Moreover, it has destructive impacts on root growth and elongation (Atal et al., 1991; Black et al., 2014).

Wheat is the most important grain source for humans worldwide, and it is cultivated on more land areas than any other field crop (FAOSTAT, 2021). Wheat Cd contamination poses a substantial health risk (Nordberg, 2009). The European Food Safety Authority has lowered the tolerable weekly intake of Cd from 7 to $2.5 \mathrm{\mu g} \mathrm{Cd}^{-1} \mathrm{~kg}^{-1}$ body-weight (Adeniji et al., 2010; Singh et al., 2011). Long-term human exposure to Cd even at a low rate causes impaired kidney function, bone demineralization, emphysema, and proteinuria, and increases the threat of lung cancer (Bernard, 2008; Nordberg, 2009).

The hazard of Cd contamination highlights the importance of breeding for Cd-tolerant and low-grain Cd wheat genotype. Noticeable genotypic differences are detected in grain-Cd accumulation in bread wheat (Clarke et al., 1997; Stolt et al., 2003; Arduini et al., 2014; Guo et al., 2018). Developing tolerant wheat genotypes to Cd-stress with low Cd uptake into grains is the most efficient approach to reduce health threats as well as mitigate its negative impacts on plant growth (Zaid et al., 2018). Breeding Cd-tolerant wheat genotypes with lower Cd content requires crossing among superior individuals followed by selection in succeeding generations based on related traits to Cd-stress (Oladzad-Abbasabadi et al., 2018). Exploitation of heterosis provides an efficient perspective for enhancing wheat $\mathrm{Cd}$ potential and tolerance to $\mathrm{Cd}$-stressed. Nevertheless, there remain several restrictions to breeding low-Cd wheat cultivars as slow and high cost of genetic improvement process as well as consuming long time. Developing low-Cd content and Cd-tolerant requires reliable understanding of natural genetic variation and inheritance of associated traits which is less characterized for hexaploid bread wheat. Therefore, the present investigation aimed at investigating the genetic diversity among bread wheat genotypes using triple RAPD and ISSR markers and assessing heterotic effects, genetic parameters, expected response from selection and prediction for low-Cd content and Cd tolerance.

\section{Materials And Methods}

\subsection{Investigating the genetic diversity among selected parents}

Twenty diverse bread wheat genotypes were screened for $\mathrm{Cd}$ tolerance in a preliminary experiment. The highly-tolerant six genotypes were selected to be crossed; namely Giza-168, Sids-6, ACSAD-925, Gemmeiza-10, ACSAD-935 and Line-1 (Table S1). The genetic diversity among selected parents was investigated using triple-RAPD and ISSR markers. DNA was extracted from young and fresh leaves $(0.1 \mathrm{~g})$ of the selected parents by the CTAB (cetyltrimethylammonium bromide). The quantity and quality of extracted DNA were measured ( $2 \mu \mathrm{l}$ ) by a NanoDrop ND-1000 UV-Vis spectrophotometer

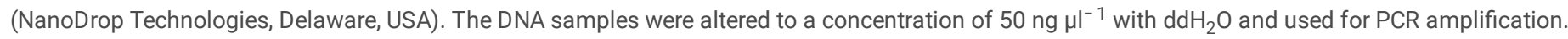

Triple-RAPD-PCR reaction was applied as described by Williams et al. (1990) in volumes of $25 \mu$ l. The reaction mixture including $10 \mathrm{mM}$ Tris-Cl, pH $8.3,50 \mathrm{mM}$ $\mathrm{KCl}, 2 \mathrm{mM} \mathrm{MgCl} 2,0.001 \%$ gelatin, $100 \mu \mathrm{M}$ of each dATP, dGTP, dCTP and dTTP (Pharmacia), $0.2 \mu$ primer, 25 ng of genomic DNA, and 0.5 unit of Taq DNA polymerase (Promega). To increase the potential of PCR reaction, different combinations of three decamer oligonucleotides had been utilized in the singleprimer PCR as suggested by Klein-Lankhorst et al. 1991 (Table 1).

Table 1. RAPD primers and ISSR primers applied for diversity screening (sequences 5'- 3 ') 


\begin{tabular}{|c|c|c|c|}
\hline RAPD & Sequences & ISSR & Sequences \\
\hline P1 & GTAGACCCG & 814 & (CT)8TG (\#814) \\
\hline P2 & GGACCCTTAC & $844 \mathrm{~A}$ & (CT)8AC (\#844A) \\
\hline P3 & GTCGCCGTCA & $844 \mathrm{~B}$ & (CT)8G (\#844B) \\
\hline P4 & GGTCCCTGAC & 17898A & (CA)6AC(\#17898A) \\
\hline P5 & TGGACCGGTG & 17898B & (CA)6GT (\#17898B) \\
\hline P6 & AGGGGTCTTG & 17899A & (CA)6AG (\#17899A) \\
\hline P7 & TTCCCCCGCT & 17899B & (CA)6GG (\#17899B) \\
\hline P8 & TTCCССССАG & HB8 & (GA)6GG (\#HB8) \\
\hline P9 & ACTTCGCCAC & HB9 & (GT)6GG (\#HB9) \\
\hline P10 & CAATCGCCGT & HB10 & (GA)6CC (\#HB8) \\
\hline P11 & AGGGAACGAG & HB11 & (GT)6CC (\#HB11) \\
\hline P12 & TGCGCCCTTC & HB12 & (CAC)3GC(\#HB12) \\
\hline P13 & TTCGCACGGG & HB13 & (GAG)3GC (\#HB13) \\
\hline P14 & GTGAGGCGTC & HB14 & (CTC)3GC (\#HB14) \\
\hline P15 & CAAACGTCGG & HB15 & (GTG)3GC (\#HB14) \\
\hline P16 & CTGCTGGGAC & & \\
\hline P17 & GTGACGTAGG & & \\
\hline P18 & CCACAGCAGT & & \\
\hline P19 & TGAGCGGACA & & \\
\hline P20 & GTGAGGCGTC & & \\
\hline
\end{tabular}

A set of fifteen ISSR primers was obtained from Metabion, Germany (Table 1). PCR amplification was applied as outlined by Dangi et al. (2004). Twenty ng of DNA was mixed with $50 \mathrm{mM} \mathrm{KCl}, 10 \mathrm{mM}$ Tris- $\mathrm{HCl} \mathrm{pH} \mathrm{7.5,} 0.5 \mathrm{mM}$ spermidine, $1.5 \mathrm{mM} \mathrm{MgCl} 2,0.1 \mathrm{mM}$ dNTPs, $0.8 \mathrm{U}$ of Taq DNA polymerase and $0.3 \mathrm{uM}$ primer in a $25 \mu \mathrm{l}$ reaction utilizing Perkin Elmer 2400 thermocycler. All used chemicals for the reaction were procured from Sigma-Aldrich, USA.

Agarose gel electrophoresis (1.6\%) was used for separating the amplified fragments. The fragments were recorded using EG-Gel Analyzer V1 software. The genetic similarity among parents was investigated by Nei's genetic distance (Nei, 1987). The dendrogram was performed using the Unweighted Pair Group Method with Arithmetic averages (UPGMA). The estimates were applied using the NTSYS-pc 2.02 software package (Numerical Taxonomy System, Exeter Software, Rohlf, 2000).

\subsection{Crossing among selected parents}

Three crosses were performed between the selected genetically diverse six parents; Giza-168×Sids-6 (1st cross), ACSAD-925×Gemmeiza-10 (2nd cross) and ACSAD-935 $\times$ Line- 1 (3rd cross). The $F_{1}$ populations were selfed to produce $F_{2}$ populations and were backcrossed with their own parents to produce $B C_{1}$ and $\mathrm{BC}_{2}$ populations. Six populations for each cross; $\mathrm{P}_{1}, \mathrm{P}_{2}, \mathrm{~F}_{1}, \mathrm{~F}_{2}, \mathrm{BC}_{1}$ and $\mathrm{BC}_{2}$ were evaluated in two adjacent experiments in a randomized complete blocks design with three replications at the experimental farm of the Faculty of Agriculture, Zagazig University, Egypt (30³4'10" N 31 $\left.34^{\prime} 20^{\prime \prime} \mathrm{E}\right)$. The first experiment was sprayed with cadmium solution at the beginning of heading stage by a concentration of $30 \mathrm{ppm} \mathrm{Cd} \mathrm{ion/liter} \mathrm{of} \mathrm{water} \mathrm{(475} \mathrm{liter/ha).} \mathrm{The} \mathrm{second}$ experiment was used as a control with pure water spraying. Seeds of six populations were sown in the fourth week of November. Rows were 2.5 - $m$ long and $20-\mathrm{cm}$ apart, while a plant to plant space was $10-\mathrm{cm}$. The recommended agricultural practices for wheat production in the region were applied.

\subsection{Measured traits}

Data were recorded on individual guarded plants for the evaluated populations. Flag leaf area was determined at the time of full emergence of main spike. Flag leaf chlorophyll content was measured by SPAD-502 apparatus. Proline content in leaves was estimated as described by Bates et al. (1973) and grain yield/plant was assessed. For measuring Cd concentration, dried grain samples were weighed and followed by digestion at $160^{\circ} \mathrm{C}$ in $0.5 \mathrm{ml}$ of concentrated glass-distilled $\mathrm{HNO}_{3}$. A mixture of $\mathrm{HNO}_{3}: \mathrm{HClO}_{4}(0.25 \mathrm{ml})$ by $1: 1$ was mixed with the acid digestion residue and the digestion was continued at $200^{\circ} \mathrm{C}$ to dryness. The dry residue was dissolved in $1 \mathrm{ml}$ of $8 \mathrm{n} \mathrm{HNO}_{3}$, then diluted 10:1 with d1 $\mathrm{H}_{2} \mathrm{O}$ and analyzed for Cd via inductively coupled argon plasma emission spectrometry (Model ICAP 61E; Thermo-Jarrell Ash, Waltham, MA, USA), (Hart et al., 2005).

\subsection{Statistical analysis and biometrical assessments}

Analysis of variance for all evaluated traits was done using SAS Software. An index of Cd sensitivity (CSI) was computed as described by Fisher and Maurer (1978) using the following equation: Cadmium Sensitivity Index (CdSI) $=\frac{\left[1-\left(\frac{Y s}{Y p}\right)\right]}{S I}$ where, Ys and Yp are the grain yield/plant of each genotype under 
stress and normal conditions, respectively. SI is stress intensity $=1-\left(\frac{\bar{y}_{s}}{\bar{y}_{\mathrm{p}}}\right), \bar{y}_{s}$ and $\bar{y} p$ are averages of grain yield for all genotypes under Cd-stressed and non-stressed conditions, in the same order. Mid-parents heterosis and standard heterosis were calculated using the formula outlined by Bitzer et al. (1982) as

follows: Mid-parents heterosis $\left(\mathrm{MPH}_{\%}\right)=\frac{[\mathrm{F} 1-\mathrm{MP}]}{M P} \times 100$. Standard heterosis $\left(\mathrm{SH}_{\%}\right)=\frac{[\mathrm{F} 1-\mathrm{Check} \text { cultivar }]}{\text { Check cultivar }} \times 100$. Inbreeding depression $=$ $\frac{[\mathrm{F} 1-\mathrm{F} 2]}{\mathrm{F} 2} \times 100$

, where, MP is mean of mid parents, and check cultivar is average of Giza-168. $F_{2}$ deviation was calculated according to Sun et al. (1972) as follows: $F_{2}$ deviation $=F_{2}-0.5\left[F_{1}+0.5\left(P_{1}+P_{2}\right)\right]$. Parent-offspring regression $\left(h^{2}\right)$, realized heritability $(R H)$, and genetic advance from selection $\left(G s_{\%}\right)$ were also computed according to Falconer (1989). The components of the genetic variance i.e. additive VD, dominance VH and environmental VE variances were estimated as described by Mather and Jinks (1982) and were utilized further to calculate frequency between dominance and recessive alleles in the parental populations $\mathrm{F}=\left(\mathrm{VBC}_{2}+\mathrm{VBC}_{1}\right)$ and the dominance at different loci $(\mathrm{F} / \sqrt{ } \mathrm{H} \times \mathrm{D})$.

\subsection{Predicting properties of new recombinant lines}

The properties of new recombinant lines that fall outside the parental range and exceeding $F_{1}$ hybrid following selfing generations were calculated using Jinks and Pooni (1976) formula. The proportion of inbreds falling outside parental range $=d / \sqrt{ } D$, the proportion of inbreds exceeding $F_{1} h y b r i d=h / \sqrt{ } D$. Also, the best inbred $(P$ max $)=m+h / \sqrt{H} \times D$ was calculated according to Hayward et al. $(1993)$ Where: $m=0.5\left(P_{1}+P_{2}\right)$, $[d]=0.5\left(P_{1}-P_{2}\right)$ and $[h]=F_{1}-m$, where $D$ is additive genetic variance and $\mathrm{H}$ is dominance genetic variance.

\section{Results And Discussion}

\subsection{Genetic diversity among selected parents}

Utilizing molecular markers increases the efficacy of classical plant breeding by assessing the genetic diversity among used parents (Milad et al., 2011; Pozniak et al., 2012; Abu Hammad et al., 2016). In the current study, genetic diversity was investigated using triple-primer RAPD and ISSR markers. TripleRAPD amplification reactions were applied using different combinations of three different decamer oligonucleotides that had been previously tested in the single-primer PCR (Table 1). In all cases, the combination of three primers (in 1: 1: 1 ratio) led to appearance of new bands that were not amplified using each primer independently (Fig. 1A). The sizes of produced fragments varied from $100 \mathrm{bp}$ to $2 \mathrm{Kbp}$. A total of 440 bands were recorded, in average $35 \pm 2 \%$ band per primer/gel, $12 \pm 2 \%$ polymorphic, $25 \pm 2 \%$ unique bands and $36 \pm 2 \%$ polymorphic (with unique), which revealed 70 to $80 \%$ polymorphism. While certain bands were monomorphic in all genotypes, there were specific bands for each one (Fig. 1A). Genetic similarity was determined by Nei's index value for all genotypes considering Triple-RAPD results, then were employed to perform dendrogram using Unweighted Pair Group Method with Arithmetic averages (UPGMA) (Fig. 1B, C). The dendrogram displayed genetic diversity among used wheat parents.

ISSR technique utilizes frequently $16-25$ bp long primers in a single primer PCR reaction focusing on multiple genomic loci to amplify principally the inter-SSR sequences of different sizes (Ziêtkiewicz et al., 1994). In the current study, a set of 50 ISSR primers was applied for preliminary screening of six wheat genotypes (Fig. 1A). However, only fifteen ISSR primers identified intraspecific variation in wheat genotypes produced on average fifteen bands per gel/primer in the range of $100 \mathrm{bp}$ to $2 \mathrm{kbp}$. Among these bands, four were polymorphic bands and sixteen were unique bands revealing polymorphism. Based on ISSR gels patterns, the similarity index values were employed to create dendrogram utilizing UPGMA. The obtained dendrogram showed different clusters displaying variation in the frequencies of SSR motifs (Fig. 1B, C). Likewise, Pozniak et al. (2012); Abu Hammad et al. (2016) and Liu et al. (2019) demonstrated the potentiality of molecular markers to distinguish the parental diversity based on Cd tolerance.

\subsection{Heterosis and $F_{2}$ deviation}

The reliability of genetic components depends mainly on the amount of genetic variability among the used parents. The obtained results indicated positive and significant relative and standard heterosis for flag leaf area in the three investigated crosses under both conditions. Likewise, leaf chlorophyll content in the $2^{\text {nd }}$ cross exhibited positive and significant relative and standard heterosis under both conditions as well as the $1^{\text {st }}$ cross under Cd-stressed while $3^{\text {rd }}$ cross for standard heterosis only under Cd-stressed (Table 2). Besides, significantly positive relative heterotic effects were observed for proline content in $1^{\text {st }}$ and $3^{\text {rd }}$ crosses under non-Cd stress and $2^{\text {nd }}$ cross only under $\mathrm{Cd}$-stressed conditions. Desirable heterosis over mid-parents or standard cultivar has been registered for grain yield/plant in the $1^{\text {st }}$ and $2^{\text {nd }}$ crosses under both conditions and the $3^{\text {rd }}$ cross only under non-Cd stressed conditions. On the other hand, negative heterosis in the desired direction was detected for $\mathrm{Cd}$ concentration in the $2^{\text {nd }}$ cross under non-Cd stressed and standard heterosis in $1^{\text {st }}$ and $2^{\text {nd }}$ crosses under $\mathrm{Cd}$-stressed as well as for $\mathrm{Cd}$ sensitivity index in $1^{\text {st }}$ and $2^{\text {nd }}$ crosses for mid-parent heterosis. These crosses accumulated lower amounts of Cd concentration rather than the other crosses i.e. $3^{\text {rd }}$ cross under both conditions which accumulated higher amounts of cadmium in grains. Cd sensitivity index displayed significant positive relative heterosis in the $3^{\text {rd }}$ cross. The obtained significant relative and standard heterosis were due to heterotic effects and dominance and/or dominancexdominance gene effects in the evaluated crosses. Likewise, significant heterotic effects for agronomic traits and Cd concentration were recorded by Clarke et al. (1997). Similarly, Awaad et al. (2013) recorded significant heterobeltiosis for flag leaf area, leaf chlorophyll content, proline content, Cd concentration and grain yield/plant under both non-Cd stressed and Cd-stressed conditions. 
Table 2

Estimates of heterosis, inbreeding depression, dominance and $F_{2}$ deviations for evaluated characters of the three wheat crosses under non-

Cd-stressed and Cd-stressed conditions.

\begin{tabular}{|c|c|c|c|c|c|c|c|c|c|}
\hline \multirow[t]{2}{*}{ Parameter } & \multicolumn{3}{|c|}{$\begin{array}{l}\text { Flag leaf area } \\
\left(\mathrm{cm}^{2}\right)\end{array}$} & \multicolumn{3}{|c|}{ Leaf chlorophyll content (SPAD value) } & \multicolumn{3}{|c|}{$\begin{array}{l}\text { Proline content } \\
\text { ( } \mu \text { moles /g FW) }\end{array}$} \\
\hline & 1st cross & 2nd cross & $\begin{array}{l}\text { 3rd } \\
\text { cross }\end{array}$ & $\begin{array}{l}\text { 1st } \\
\text { cross }\end{array}$ & 2nd cross & $\begin{array}{l}\text { 3rd } \\
\text { cross }\end{array}$ & $\begin{array}{l}\text { 1st } \\
\text { Cross }\end{array}$ & 2nd cross & 3rd cross \\
\hline
\end{tabular}

\begin{tabular}{|c|c|c|c|c|c|c|c|c|c|}
\hline \multirow[b]{2}{*}{ Mid-parents heterosis } & \multicolumn{9}{|c|}{ Non-Cd-stressed conditions } \\
\hline & $12.74^{\star \star}$ & $10.13^{\star \star}$ & $16.71^{\star *}$ & 0.72 & $4.65^{\star \star}$ & $-4.88^{\star \star}$ & $44.57^{\star \star}$ & $-4.62^{*}$ & $11.44^{\star *}$ \\
\hline Standard heterosis & $7.13^{*}$ & $31.22^{\star \star}$ & 33.31 & 2.95 & $6.45^{\star \star}$ & -1.09 & $13.68^{*}$ & -0.31 & $-15.46^{*}$ \\
\hline Inbreeding depression & 2.72 & $19.02^{\star \star}$ & $5.39^{\star}$ & $-4.91^{\star \star}$ & $3.03^{* *}$ & 1.25 & $-29.32^{\star \star}$ & $9.69^{*}$ & $16.79^{\star \star}$ \\
\hline Dominance deviation & $5.40^{\star}$ & $4.56^{*}$ & $7.70^{\star *}$ & 0.35 & $2.20^{\star}$ & $-2.71^{*}$ & $0.41^{\star \star}$ & -0.16 & $0.28^{*}$ \\
\hline \multirow[t]{2}{*}{$\mathrm{F}_{2}$ deviation } & $1.40^{*}$ & $-7.15^{\star *}$ & 0.95 & $2.58^{*}$ & -0.40 & $-2.03^{*}$ & $0.59^{\star *}$ & $-0.39^{*}$ & $-0.31^{*}$ \\
\hline & \multicolumn{9}{|c|}{ Cd-stressed conditions } \\
\hline Mid-parents heterosis & $24.37^{\star \star}$ & $10.33^{*}$ & $19.41^{* \star}$ & $21.48^{\star *}$ & $4.24^{*}$ & 0.51 & $11.35^{\star \star}$ & -1.53 & $-5.53^{\star \star}$ \\
\hline Standard heterosis & $18.04^{\star *}$ & $31.17^{\star \star}$ & $44.11^{\star *}$ & $27.59^{\star \star}$ & $6.24^{*}$ & $4.78^{*}$ & -0.96 & $6.94^{*}$ & $-16.07^{\star}$ \\
\hline Inbreeding depression & $6.43^{*}$ & $19.77^{\star \star}$ & $6.63^{*}$ & -0.59 & $2.03^{\star \star}$ & $-1.79^{*}$ & $7.77^{*}$ & $35.34^{*}$ & $15.43^{\star \star}$ \\
\hline Dominance deviation & $8.90^{\star *}$ & $3.98^{*}$ & $8.09^{\star *}$ & $7.85^{\star *}$ & $1.80^{*}$ & 0.26 & $0.21^{\star *}$ & -0.08 & $-0.22^{*}$ \\
\hline \multirow[t]{3}{*}{$F_{2}$ deviation } & $1.53^{*}$ & $-6.41^{* *}$ & 0.75 & $3.67^{\star *}$ & 0.00 & $1.03^{*}$ & -0.06 & $-1.84^{*}$ & $-0.69^{*}$ \\
\hline & \multicolumn{3}{|c|}{$\begin{array}{l}\text { Cd concentration } \\
\text { (mg Cd/kg DW) }\end{array}$} & \multicolumn{2}{|c|}{$\begin{array}{l}\text { Grain yield per plant } \\
\text { (g) }\end{array}$} & & \multicolumn{3}{|c|}{ Cd sensitivity index } \\
\hline & \multicolumn{9}{|c|}{ Non-Cd-stressed conditions } \\
\hline Mid-parents heterosis & $11.42^{\star \star}$ & $-4.08^{*}$ & $15.19^{* *}$ & $27.12^{\star *}$ & $26.33^{\star \star}$ & $15.96^{\star \star}$ & $-23.74^{\star}$ & $-9.83^{*}$ & $96.72^{\star \star}$ \\
\hline Standard heterosis & $2.04^{*}$ & $-16.96^{\star *}$ & $51.23^{\star *}$ & $10.21^{*}$ & $40.16^{\star *}$ & $-15.41^{*}$ & $-32.59^{\star}$ & $-41.05^{\star *}$ & $-57.87^{* *}$ \\
\hline Inbreeding depression & $-18.50^{\star *}$ & 2.13 & $17.59^{* *}$ & $12.24^{* *}$ & 0.56 & $10.44^{*}$ & $48.74^{\star *}$ & $7.98^{*}$ & $28.23^{\star \star}$ \\
\hline Dominance deviation & $0.021^{*}$ & -0.01 & $0.04^{*}$ & $1.94^{*}$ & $1.86^{*}$ & $1.35^{\star}$ & $-0.48^{* *}$ & -0.15 & 0.48 \\
\hline \multirow[t]{2}{*}{$F_{2}$ deviation } & $0.05^{\star *}$ & -0.01 & $-0.03^{*}$ & -0.14 & $0.88^{*}$ & -0.35 & $-0.99^{* *}$ & $-0.18^{*}$ & -0.04 \\
\hline & \multicolumn{9}{|c|}{ Cd-stressed conditions } \\
\hline Mid-parents heterosis & 0.53 & $3.52^{*}$ & $9.39^{*}$ & $44.69^{* *}$ & $28.21^{\star \star}$ & $-2.85^{*}$ & & & \\
\hline Standard heterosis & $-7.04^{* *}$ & $-13.04^{*}$ & $15.75^{\star}$ & $33.40^{\star *}$ & $59.69^{\star *}$ & $-30.66^{\star *}$ & & & \\
\hline Inbreeding depression & $-3.03^{*}$ & $16.67^{\star \star}$ & $13.07^{\star *}$ & $-3.15^{*}$ & $-1.24^{*}$ & $1.26^{*}$ & & & \\
\hline Dominance deviation & 0.01 & $0.03^{*}$ & $0.08^{*}$ & $2.06^{\star *}$ & $1.59^{*}$ & -0.21 & & & \\
\hline$F_{2}$ deviation & $0.02^{* *}$ & $-0.12^{*}$ & $-0.08^{*}$ & $1.24^{\star *}$ & $0.89^{*}$ & -0.19 & & & \\
\hline
\end{tabular}

Inbreeding depression and dominance deviations displayed a similar trend and were found to be significantly positive for flag leaf area in the three crosses, leaf chlorophyll content in the $2 \mathrm{nd}$ cross and Cd concentration in the $3 \mathrm{rd}$ cross under both conditions. Similarly, inbreeding depression and dominance deviations were significantly positive for proline content in 1 st cross and Cd concentration in 2nd cross under Cd-stressed as well as grain yield/plant in $1 \mathrm{st}$ and 3 rd crosses under non-Cd stressed conditions. These results could be discussed on the basis of heterotic effects and dominance and/or dominance $x$ dominance gene effects in the assessed crosses. On the contrary, decreasing alleles were involved in the inheritance of Cd concentration in 1 st cross under both conditions and grain yield/plant in 1 st and 2 nd crosses under Cd-stressed conditions. Otherwise, dominance deviation exhibited significantly positive values for grain yield/plant in 2nd cross under non-Cd stressed condition and 1st and 2nd crosses under Cd-stressed. Moreover, dominance deviation exhibited negative and significant values for leaf chlorophyll content in 3rd cross under non-Cd stressed and proline content under Cd-stressed as well as Cd 
sensitivity index in the 1 st cross (Table 2). $F_{2}$ deviation exhibited significant positive estimates for flag leaf area, leaf chlorophyll content and Cd concentration in 1st cross; grain yield/plant in 2nd cross under both conditions; leaf chlorophyll content in 3rd cross under Cd-stressed. Otherwise, it was negative and significant for flag leaf area, Cd concentration in 3rd cross; proline content in 2nd and 3rd crosses under both conditions; leaf chlorophyll content in 3rd cross under non-Cd stressed as well as Cd sensitivity index in 1st and 2nd crosses.

\subsection{Gene effect and heritability}

The nature of gene action and heritability play an important role in identifying the appropriate breeding method to improve economic traits through breeding programs. Genetic parameters controlling cadmium stress tolerance and related traits are presented in Table (3). The additive gene effect [d] was significant and involved in the genetics of flag leaf area in 1st cross and proline content in 3rd cross under non-Cd stress as well as in 1st cross under Cd-stress conditions. Likewise, significant additive gene effect was detected for $\mathrm{Cd}$ concentration in 1 st cross under both conditions and 2nd and 3rd crosses under nonCd stressed conditions. Hereby, reflecting in an h/d ratio was less than unity, showing no over dominance. Liu et al. (2019) revealed the significance of additive effect with high heritability for grain Cd concentration suggests the opportunity of breeding consistently low-Cd wheat cultivars crossways environments.

The dominance gene effect [h] which indicate the presence of heterotic effects and dominance and/or dominancexdominance gene effects was significant and involved in controlling flag leaf area, leaf chlorophyll content in the three crosses; grain yield/plant in 1st and 2nd crosses under both conditions; proline content in 1st and 2nd crosses under non-Cd stressed and 2nd and 3rd under Cd-stressed; Cd concentration in 1st cross under non-Cd stressed and 2nd and 3rd crosses under $\mathrm{Cd}$-stressed and $\mathrm{Cd}$ sensitivity index in 1 st and $3 \mathrm{rd}$ crosses, reflecting potency ratio $\mathrm{h} / \mathrm{d}$ was more than unity (Tables 3 and 4 ). These results indicated the presence of dominant genes which increase expression between the parents and ensure transgressive segregation for these traits in the $F_{2}$ generation. Otherwise, $\mathrm{h} / \mathrm{d}$ ratio was less than unity for proline content in 3rd cross and Cd concentration in 2nd and 3rd crosses under non-Cd stressed condition as well as for proline content in $1 \mathrm{st}$ cross and $\mathrm{Cd}$ concentration in the three crosses under Cd-stressed indicating partial dominance occurred. The additive and over-dominance type of genetic architecture are previously detected for flag leaf area; leaf chlorophyll content, Cd content, proline content and grain yield/plant by Awaad et al. (2013). Furthermore, EL-Gharbawy et al. (2015) disclosed that both additive and dominance gene effects were involved in controlling $\mathrm{Cd}$ and proline contents with a greater role for dominance and relatively high narrow-sense heritability in respect to proline content. On the other hand, Dunwei et al. (2012) manifested that Cd tolerance in wheat was governed by additive genetic variance. 
Table 3

Measured genetics parameters controlling Cd-stress tolerance in the evaluated traits of three wheat crosses under non-Cd-stressed and Cd-stressed conditions.

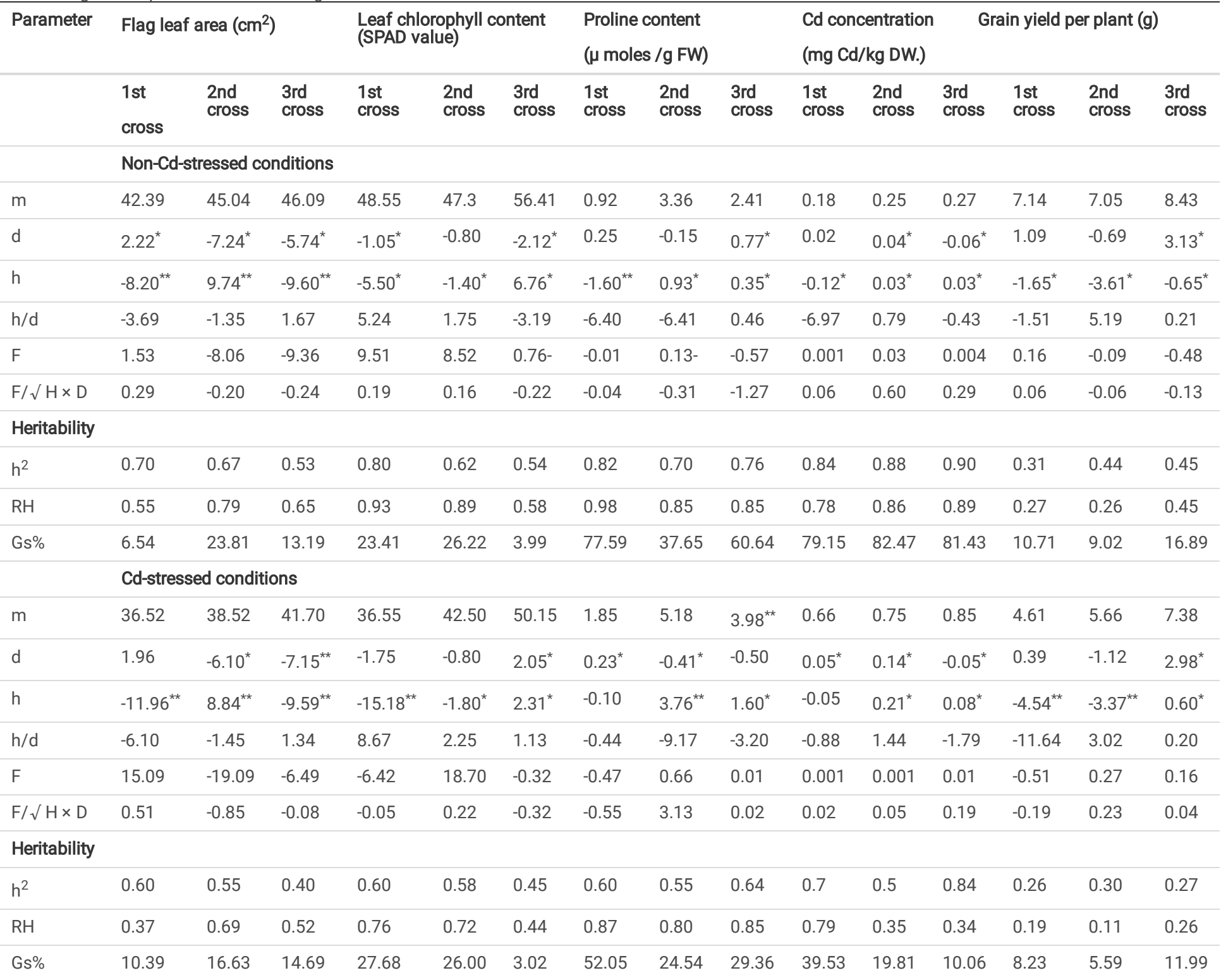

$\mathrm{h}^{2}$ is heritability estimates from parent-offspring regression, $\mathrm{RH}$ is realized heritability and $\mathrm{Gs} \%$ is genetic advance from selection

Table 4

Estimated genetic parameters for Cd sensitivity index of three wheat crosses under non-Cd-stressed and Cd-stressed conditions.

\begin{tabular}{|llll|}
\hline Parameter & 3rd cross & 2nd cross & 1st cross \\
\hline m & 2.03 & 1.50 & 0.49 \\
d & 0.27 & 0.59 & -0.11 \\
\hline h & $1.24^{\star *}$ & $0.51^{*}$ & $-0.41^{\text {** }}$ \\
\hline h/d & 4.64 & 0.87 & 3.63 \\
\hline F & 0.16 & 0.70 & 0.10 \\
\hline F/ H $\times$ D & 0.11 & 0.45 & 0.08 \\
\hline Heritability & & & \\
\hline h ${ }^{2}$ & 0.28 & 0.45 & 0.32 \\
\hline RH & 0.20 & 0.24 & 0.20 \\
\hline Gs \% & 76.11 & 79.19 & 83.55 \\
\hline
\end{tabular}


Table 5

Predicted properties of recombinant lines exceeding parental range for evaluated traits of three wheat crosses under non-Cd stressed and Cd-stressed conditions.

\begin{tabular}{|c|c|c|c|c|c|c|c|c|c|}
\hline \multirow[t]{2}{*}{ Parameter } & \multicolumn{3}{|c|}{ Flag leaf area $\left(\mathrm{cm}^{2}\right)$} & \multicolumn{3}{|c|}{ Leaf chlorophyll content (SPAD value) } & \multicolumn{3}{|c|}{ Proline content ( $\mu$ moles /g. FW) } \\
\hline & 1 st cross & 2nd cross & 3rd cross & 1st cross & 2nd cross & 3 rd cross & 1st cross & 2nd cross & 3 rd cross \\
\hline & \multicolumn{9}{|c|}{ Non-Cd-stressed conditions } \\
\hline $\mathrm{m}=\mathrm{F} 2$ & $\begin{array}{l}46.50 \pm \\
1.85\end{array}$ & $\begin{array}{l}40.17 \pm \\
1.75\end{array}$ & $\begin{array}{l}50.90 \pm \\
2.23\end{array}$ & $\begin{array}{l}51.30 \pm \\
1.45\end{array}$ & $\begin{array}{l}48.00 \pm \\
3.09\end{array}$ & $\begin{array}{l}53.03 \pm \\
1.18\end{array}$ & $\begin{array}{l}1.720 \pm \\
0.33\end{array}$ & $\begin{array}{l}2.890 \pm \\
0.45\end{array}$ & $\begin{array}{l}2.230 \pm \\
0.43\end{array}$ \\
\hline $\begin{array}{l}\text { Range of inbreds } m \pm \\
2 \sqrt{D}\end{array}$ & $\begin{array}{l}41.57- \\
51.43\end{array}$ & $\begin{array}{l}23.95- \\
56.39\end{array}$ & $\begin{array}{l}36.50- \\
65.29\end{array}$ & $\begin{array}{l}34.24- \\
68.36\end{array}$ & $\begin{array}{l}24.93- \\
71.07\end{array}$ & $\begin{array}{l}48.58- \\
57.48\end{array}$ & $0.13-3.57$ & $1.12-4.66$ & $0.21-4.25$ \\
\hline Probability $(\mathrm{d} / \sqrt{\mathrm{D}})$ & 0.90 & 0.89 & 0.79 & 0.12 & 0.07 & 0.95 & 0.27 & 0.164 & 0.757 \\
\hline \multirow[t]{2}{*}{ Proportion of inbreds * } & 18.41 & 18.67 & 21.48 & 45.22 & 47.21 & 17.11 & 39.36 & 43.64 & 22.36 \\
\hline & \multicolumn{9}{|c|}{ Cd-stressed conditions } \\
\hline $\mathrm{m}=\mathrm{F} 2$ & $\begin{array}{l}42.50 \pm \\
1.45\end{array}$ & $\begin{array}{l}34.10 \pm \\
1.90\end{array}$ & $\begin{array}{l}46.50 \pm \\
2.07\end{array}$ & $\begin{array}{l}44.14 \pm \\
1.42\end{array}$ & $\begin{array}{l}43.40 \pm \\
1.15\end{array}$ & $\begin{array}{l}51.30 \pm \\
1.00\end{array}$ & $\begin{array}{l}1.900 \pm \\
0.19\end{array}$ & $\begin{array}{l}3.300 \pm \\
0.42\end{array}$ & $\begin{array}{l}3.18 \pm \\
0.224\end{array}$ \\
\hline $\begin{array}{l}\text { Range of inbreds } m \pm \\
2 \sqrt{D}\end{array}$ & $\begin{array}{l}34.24- \\
50.76\end{array}$ & $\begin{array}{l}22.39- \\
45.82\end{array}$ & $\begin{array}{l}27.09- \\
65.91\end{array}$ & $\begin{array}{l}20.99- \\
67.28\end{array}$ & $\begin{array}{l}21.29- \\
65.51\end{array}$ & $\begin{array}{l}47.39- \\
55.21\end{array}$ & $0.03-3.77$ & $1.63-4.97$ & $1.52-4.84$ \\
\hline Probability $(d / \sqrt{ } D)$ & 0.48 & 1.04 & 0.74 & 0.15 & 0.07 & 1.05 & 0.25 & 0.49 & 0.60 \\
\hline \multirow[t]{3}{*}{ Proportion of inbreds * } & 31.56 & 14.92 & 22.97 & 44.04 & 47.21 & 14.69 & 40.13 & 31.21 & 24.51 \\
\hline & \multicolumn{3}{|c|}{ Cd concentration (mg Cd/kg DW.) } & \multicolumn{3}{|c|}{ Grain yield per plant (g) } & \multicolumn{3}{|c|}{ Cadmium sensitivity index } \\
\hline & 1 st cross & 2nd cross & 3rd cross & 1st cross & 2nd cross & 3 rd cross & 1 st cross & 2nd cross & 3rd cross \\
\hline & \multicolumn{9}{|c|}{ Non-Cd-stressed conditions } \\
\hline $\mathrm{m}=\mathrm{F} 2$ & $\begin{array}{l}0.24 \pm \\
0.041\end{array}$ & $0.23 \pm 0.05$ & $0.25 \pm 0.05$ & $7.96 \pm 0.43$ & $8.85 \pm 0.42$ & $8.75 \pm 0.64$ & 0.79 & 1.25 & 0.69 \\
\hline $\begin{array}{l}\text { Range of inbreds } m \pm \\
2 \sqrt{D}\end{array}$ & $0.02-0.49$ & $0.02-0.48$ & $0.69-1.19$ & $\begin{array}{l}4.84- \\
11.08\end{array}$ & $\begin{array}{l}6.79- \\
10.91\end{array}$ & $\begin{array}{l}5.02- \\
12.48\end{array}$ & $1.66-3.24$ & $1.25-3.74$ & $1.37-2.75$ \\
\hline Probability $(d / \sqrt{ } D)$ & 0.13 & 0.31 & 0.134 & 0.701 & 0.674 & 1.674 & 0.267 & 0.586 & -0.115 \\
\hline \multirow[t]{2}{*}{ Proportion of inbreds * } & 44.83 & 37.83 & 44.83 & 24.19 & 25.14 & 4.75 & 41.29 & 31.92 & 45.62 \\
\hline & \multicolumn{9}{|c|}{ Cd-stressed conditions } \\
\hline $\mathrm{m}=\mathrm{F} 2$ & $0.68 \pm 0.06$ & $\begin{array}{l}0.650 \pm \\
0.124\end{array}$ & $0.81 \pm 0.07$ & $6.88 \pm 0.40$ & $7.34 \pm 0.56$ & $7.08 \pm 0.45$ & & & \\
\hline $\begin{array}{l}\text { Range of inbreds } m \pm \\
2 \sqrt{D}\end{array}$ & $0.24-1.12$ & $0.36-0.94$ & $0.69-0.91$ & $4.41-9.35$ & $5.78-8.89$ & $\begin{array}{l}3.51- \\
10.65\end{array}$ & & & \\
\hline Probability $(d / \sqrt{ } D)$ & 0.25 & 0.98 & 0.85 & 0.32 & 1.43 & 1.67 & & & \\
\hline Proportion of inbreds * & 40.52 & 16.35 & 19.77 & 37.45 & 7.64 & 4.85 & & & \\
\hline
\end{tabular}

$F$ values indicate the frequency between dominance and recessive alleles in the parental populations. Also, $F / \sqrt{ }(H \times D)$ provided evidence that the dominance at different loci particularly consistent in sign or magnitude. $F$ value and $F / \sqrt{ }(H \times D)$ ratio were positive for flag leaf area in $1^{\text {st }}$ cross; leaf chlorophyll content in $2^{\text {nd }}$ cross; $\mathrm{Cd}$ concentration as well as $\mathrm{Cd}$ sensitivity index in the three crosses under both environments and leaf chlorophyll content and grain yield/plant in $1^{\text {st }}$ cross under non-Cd stressed conditions. The positive $\mathrm{F}$ value indicates that dominant alleles were more frequent than recessive ones in the parental populations. Whereas, both parameters were negative for flag leaf area in $2^{\text {nd }}$ and $3^{\text {rd }}$ crosses; leaf chlorophyll content in $3^{\text {rd }}$ cross; proline content in $1^{\text {st }}$ cross under both conditions; proline content and grain yield/plant in $2^{\text {nd }}$ and $3^{\text {rd }}$ crosses under non-Cd stressed conditions. Negative $F$ values revealed that recessive alleles were more frequent than dominant ones in the parental populations.

Heritability computed from parent-offspring regression $\left(\mathrm{h}^{2}\right)$ and realized heritability (RH) are shown in Tables (3) and (4). Estimates from parent-offspring regression $\left(\mathrm{h}^{2}\right)$ were high $(<50 \%)$ for flag leaf area, leaf chlorophyll content, proline content and Cd concentration in most studied crosses under both conditions. While, it was moderate for flag leaf area and leaf chlorophyll content under Cd-stressed, also varied from low to moderate for grain yield/plant and $\mathrm{Cd}$ sensitivity index. Realized heritability $(\mathrm{RH})$ recorded values less than $\mathrm{h}^{2}$. Generally, $\mathrm{RH}$ was high for flag leaf area, leaf chlorophyll content, proline content and Cd concentration under non-Cd stressed conditions. However, it varied from moderate (37.4\%) to high (87.0\%) for that traits under Cd-stress as well as low for grain yield/plant and $\mathrm{Cd}$ sensitivity index under both environments. Also, low to moderate heritability estimates were registered in the remaining crosses for the different traits under both conditions. Genetic advance as percentage of the population mean was high for proline content, Cd concentration under non-Cd stress and moderate under $\mathrm{Cd}$-stress and detected to be high for $\mathrm{Cd}$ sensitivity index, and varied from low to moderate for the remaining traits, under both conditions. The simple inheritance based on high heritability and genetic advance observed herein indicates substantial progress could be achieved through 
selection for low Cd concentration (Clarke et al., 2002; Ishikawa et al. 2010; Oladzad-Abbasabadi et al. 2018 and Liu et al. 2019). Similar results were recorded for morpho-physiological traits, Cd concentration and grain yield/plant by Clarke et al. (1997); Awaad (2003) and Awaad et al. (2010).

\subsection{Predicting properties of new recombinant lines}

Predicted properties of new recombinant lines that fall outside the parental range and exceeding F1 hybrid are presented in Tables (5) and (6). The range of inbreds $m \pm 2 \sqrt{ } D$ was lower for flag leaf area, leaf chlorophyll content and grain yield/plant under Cd-stress compared with non-Cd stress conditions as a result of $\mathrm{Cd}$ effect on gene action. On the contrary, $\mathrm{m} \pm 2 \sqrt{\mathrm{D}}$ under $\mathrm{Cd}$-stress was lower for proline content and $\mathrm{Cd}$ concentration rather than non-Cd stress, reinforcing the possibility to isolate great number of lines more tolerant to $\mathrm{Cd}$ pollution after selfing generations. The results exhibited expected transgressive segregates that outperform the parental range. The highest percentages of such segregants under non-Cd stressed conditions were recorded by 3 rd cross for flag leaf area (21.48\%) and Cd concentration (44.83\%) while 2 nd cross for leaf chlorophyll content (47.21\%), proline content (43.64\%) and grain yield/plant (25.14\%). Similarly, 3rd cross displayed highest percentages of segregants for cadmium sensitivity index (45.62\%). On the other hand, under Cd-stressed conditions, the highest percentage of recombinant lines exceeding parental range was recorded by 1 st cross for flag leaf area was (31.56\%), proline content (40.13\%), Cd concentration (40.52\%) and grain yield/plant (37.45\%). While 2 nd cross for leaf chlorophyll content (47.21\%). The recombinants that showed stability from non-Cd stressed to Cd-stressed conditions were assigned for 2nd cross in leaf chlorophyll content and 3rd cross for grain yield/plant, but fluctuated from nonCd stressed to Cd-stressed in the other crosses.

The highest proportion of inbreds exceeding F1 under non-Cd stressed was recorded by 2nd cross for flag leaf area (11.51\%), leaf chlorophyll content (45.22\%), while by 3rd cross for proline content (36.32\%), Cd concentration (47.61\%), grain yield/plant (36.32\%) and Cd sensitivity index (34.83\%) (Table 6). Moreover, under Cd-stress the highest proportions exceeding F1 was recorded by 3rd cross for flag leaf area was (48.80\%) and grain yield/plant (36.69\%), while 2 nd cross for leaf chlorophyll content (43.64\%) and 1st cross for proline content (45.62\%) and Cd concentration (41.29\%). The best-inbred line (P max) that will have all favorable alleles tended to decrease from non-Cd stressed to Cd-stressed as a result of Cd effect (Table 6). P max was recorded by 3 rd cross for flag leaf area, Cd concentration and grain yield/plant, while 2nd cross for leaf chlorophyll content and proline content under non-Cd stressed. Whereas under Cd-stressed, the best-inbred line ( $\mathrm{P}$ max) was registered by 2 nd cross for flag leaf area, leaf chlorophyll content, proline content and Cd concentration while 3rd cross for grain yield/plant. Similar interpretation was stated by Mather and Jinks (1982) and also Awaad (2002) elucidated high proportion of recombinants falling outside parental range and exceeding F1 for grain yield/plant and morpho-physiological traits.

Table 6. Predicted properties of recombinant lines exceeding $F_{1}$ for evaluated traits of the three wheat crosses under non-Cd-stressed and Cd-stressed conditions.

\begin{tabular}{|c|c|c|c|c|c|c|c|c|c|c|c|c|c|c|c|c|}
\hline \multirow[t]{2}{*}{ Parameters } & \multicolumn{3}{|c|}{ Flag leaf area $\left(\mathrm{cm}^{2}\right)$} & \multicolumn{3}{|c|}{$\begin{array}{l}\text { Leaf chlorophyll content } \\
\text { (SPAD value) }\end{array}$} & \multicolumn{3}{|c|}{$\begin{array}{l}\text { Proline content ( } \mu \\
\text { moles /g. FW) }\end{array}$} & \multicolumn{3}{|c|}{$\begin{array}{l}\text { Cd concentration } \\
\text { (mg Cd/kg DW) }\end{array}$} & \multicolumn{3}{|c|}{$\begin{array}{l}\text { Grain yield per plant } \\
\text { (g.) }\end{array}$} & \multirow{2}{*}{$\begin{array}{l}\text { Cad } \\
\text { ind } \epsilon \\
1^{\text {st }} \\
\text { cros }\end{array}$} \\
\hline & $\begin{array}{l}1^{\text {st }} \\
\text { cross }\end{array}$ & $\begin{array}{l}2^{\text {nd }} \\
\text { cross }\end{array}$ & $\begin{array}{l}3^{\text {rd }} \\
\text { cross }\end{array}$ & $\begin{array}{l}1^{\text {st }} \\
\text { cross }\end{array}$ & $\begin{array}{l}2^{\text {nd }} \\
\text { cross }\end{array}$ & $\begin{array}{l}3^{\text {rd }} \\
\text { cross }\end{array}$ & $\begin{array}{l}1^{\text {st }} \\
\text { cross }\end{array}$ & $\begin{array}{l}2^{\text {nd }} \\
\text { cross }\end{array}$ & $\begin{array}{l}3^{\text {rd }} \\
\text { cross }\end{array}$ & $\begin{array}{l}1^{\text {st }} \\
\text { cross }\end{array}$ & $\begin{array}{l}2^{\text {nd }} \\
\text { cross }\end{array}$ & $\begin{array}{l}3^{\text {rd }} \\
\text { cross }\end{array}$ & $\begin{array}{l}1^{\text {st }} \\
\text { cross }\end{array}$ & $\begin{array}{l}2^{\text {nd }} \\
\text { cross }\end{array}$ & $\begin{array}{l}3^{\text {rd }} \\
\text { cross }\end{array}$ & \\
\hline & \multicolumn{16}{|c|}{ Non-Cd-stressed conditions } \\
\hline $\begin{array}{l}\text { Probability } \\
(\mathrm{h} / \sqrt{ } \mathrm{D})\end{array}$ & 3.33 & 1.20 & 1.33 & 0.65 & 0.12 & 3.04 & 1.73 & 1.05 & 0.35 & 0.91 & 0.25 & 0.06 & 1.06 & 3.50 & 0.35 & 1.01 \\
\hline $\begin{array}{l}\text { Proportion } \\
\text { of inbreds }\end{array}$ & 0.05 & 11.51 & 9.18 & 25.79 & 45.22 & 0.12 & 4.18 & 14.69 & 36.32 & 18.14 & 40.13 & 47.61 & 14.46 & 0.23 & 36.32 & 15.6 \\
\hline \multirow[t]{2}{*}{ P Max } & 54.87 & 66.44 & 71.22 & 73.72 & 120.29 & 78.10 & 4.82 & 6.14 & 6.06 & 0.33 & 0.44 & 1.48 & 7.41 & 6.26 & 9.31 & 1.45 \\
\hline & \multicolumn{16}{|c|}{ Cd-stressed conditions } \\
\hline $\begin{array}{l}\text { Probability } \\
(h / \sqrt{D})\end{array}$ & 2.90 & 1.51 & 0.03 & 1.31 & 0.16 & 1.18 & 0.11 & 4.49 & 1.93 & 0.22 & 1.42 & 1.52 & 3.67 & 4.33 & 0.34 & \\
\hline $\begin{array}{l}\text { Proportion } \\
\text { of inbreds }\end{array}$ & 0.19 & 6.55 & 48.80 & 9.51 & 43.64 & 11.90 & 45.62 & 0.00 & 2.68 & 41.29 & 7.78 & 6.43 & 0.01 & 0.00 & 36.69 & \\
\hline P Max & 26.39 & 64.96 & 55.97 & 46.45 & 64.94 & 46.49 & 2.12 & 16.88 & 3.97 & 0.71 & 1.22 & 0.53 & 3.96 & 3.75 & 5.90 & \\
\hline
\end{tabular}

* Proportion of inbreds exceeding F1

\section{Declarations}

Author contribution: H.A.A, A.M.A., A.M.M., E.S.A.M. and E.M. conceived and designed the study; H.A.A, A.M.A., A.M.M., E.S.A.M. and E.M. performed the experiments; H.A.A, A.M.A. and E.M. analyzed the data; H.A.A, A.M.A. and E.M. interpreted the data of the experiments; H.A.A, A.M.A. and E.M. drafted the manuscript; H.A.A, A.M.A. and E.M. edited and revised manuscript, all authors approved the final version of the manuscript.

Funding: This research received no external funding

Data availability: The datasets used or analyzed during the current study are available from the corresponding author on reasonable request

Ethics approval and consent to participate Not applicable

Consent for publication Not applicable

Page $9 / 13$ 
Competing interests The authors declare no competing interests

\section{References}

1. AbuHammad WA, Mamidi S, Kumar A, Pirseyedi S, Manthey FA, Kianian SF, Alamri MS, Mergoum M, Elias EM (2016) Identification and validation of a major cadmium accumulation locus and closely associated SNP markers in North Dakota durum wheat cultivars. Mol Breed 36(112):1-15

2. Adeniji BA, Budimir-Hussey MT, Macfie SM (2010) Production of organic acids and adsorption of Cd on roots of durum wheat (Triticum turgidum L. var. durum). Acta Physiol Plant 32:1063-1072

3. Arduini I, Masoni A, Mariotti M, Pana S, Ercoli L (2014) Cadmium uptake and translocation in durum wheat varieties differing in grain-Cd accumulation. Plant Soil Environ 60:43-49

4. Atal N, Saradhi PP, Mohanty P (1991) Inhibition of the chloroplast photochemical reactions by treatment of wheat seedlings with low concentrations of cadmium: Analysis of electron transport activities and changes in fluorescence yield. Plant Cell Physiol 32:943-951

5. Awaad H (2002) Genetic analysis, response to selection and prediction of new recombinant lines in bread wheat, Triticum aestivum L. Zagazig J Agric Res, $1343-1365$

6. Awaad H (2003) Assessment of some genetic parameters using diallel cross fashion and their implications in breeding programs of bread wheat, Triticum aestivum L. Zagazig J Agric Res, 1123-1141

7. Awaad H, Youssef M, Moustafa E (2010) Identification of genetic variation among bread wheat genotypes for lead tolerance using morpho-physiological and molecular markers. Am J Sci 6:1142-1153

8. Awaad HA, Morsy A, Moustafa E (2013) Genetic system controlling cadmium stress tolerance and some related characters in bread wheat. Zagazig J Agric Res 40:647-660

9. Bates LS, Waldren RP, Teare ID (1973) Rapid determination of free proline for water-stress studies. Plant Soil 39:205-207

10. Bernard A (2008) Cadmium \& its adverse effects on human health. Indian J Med Res 128:557-564

11. Bitzer MJ, Patterson FL, Nyquist WE (1982) Hybrid vigor and combining ability in a high-low yielding, eight-parent diallel cross of soft red winter wheat 1. Crop Sci 22:1126-1129

12. Black A, McLaren RG, Speir TW, Clucas L, Condron LM (2014) Gradient differences in soil metal solubility and uptake by shoots and roots of wheat (T. aestivum). Biol Fertil Soils 50:685-694

13. Chugh LK, Sawhney SK (1999) Photosynthetic activities of Pisum sativum seedlings grown in presence of cadmium. Plant Physiol Biochem 37:297-303

14. Ci D, Jiang D, Li S, Wollenweber B, Dai T, Cao W (2012) Identification of quantitative trait loci for cadmium tolerance and accumulation in wheat. Acta Physiol Plant 34:191-202

15. Clarke JM, Leisle D, Kopytko GL (1997) Inheritance of cadmium concentration in five durum wheat crosses. Crop Sci 37:1722-1726

16. Clarke JM, Norvell WA, Clarke FR, Buckley WT (2002) Concentration of cadmium and other elements in the grain of near-isogenic durum lines. Can J Plant Sci 82:27-33

17. Dangi RS, Lagu MD, Choudhary LB, Ranjekar PK, Gupta VS (2004) Assessment of genetic diversity in Trigonella foenum-graecum and Trigonella caerulea using ISSR and RAPD markers. BMC Plant Biol 4:1-11

18. Dong Q, Fang J, Huang F, Cai K (2019) Silicon amendment reduces soil cd availability and Cd uptake of two pennisetum species. Int J Environ Res Public Health 16:1624

19. El Gharbawy SS, Abdulhamid M, Aly R, Salem A (2015) Combining ability and gene action for grain yield and its chemical composition under normal condition and heavy metal stress in bread wheat. Zagazig J Agric Res 42:415-429

20. Falconer D (1989) Introduction to quantitative genetics, 3rd edn. Longman Scientific \& Technical John Wiley and Sons. Inc., New York, Harlow

21. Fischer RA, Maurer R (1978) Drought resistance in spring wheat cultivars. I. Grain yield responses. Aust J Agric Res 29:897-912

22. Guo G, Lei M, Wang Y, Song B, Yang J (2018) Accumulation of As, Cd, and Pb in sixteen wheat cultivars grown in contaminated soils and associated health risk assessment. Int J Environ Res Public Health 15:2601

23. Hart JJ, Welch RM, Norvell WA, Clarke JM, Kochian LV (2005) Zinc effects on cadmium accumulation and partitioning in near-isogenic lines of durum wheat that differ in grain cadmium concentration. New Phytol 167:391-401

24. Hayward MD, Bosemark NO, Romagosa T (2012) Plant breeding: principles and prospects. Springer Science \& Business Media

25. Ishikawa S, Abe T, Kuramata M, Yamaguchi M, Ando T, Yamamoto T, Yano M (2010) A major quantitative trait locus for increasing cadmium-specific concentration in rice grain is located on the short arm of chromosome 7. J Exp Bot 61:923-934

26. Jinks JL, Pooni HS (1976) Predicting the properties of recombinant inbred lines derived by single seed descent. Heredity 36:253-266

27. Klein-Lankhorst RM, Vermunt A, Weide R, Liharska T, Zabel P (1991) Isolation of molecular markers for tomato (L. esculentum) using random amplified polymorphic DNA (RAPD). Theor Appl Genet 83:108-114

28. Konate A, He X, Zhang Z, Ma Y, Zhang P, Alugongo G, Rui Y (2017) Magnetic $\left(\mathrm{Fe}_{3} \mathrm{O}_{4}\right)$ nanoparticles reduce heavy metals uptake and mitigate their toxicity in wheat seedling. Sustainability 9:790

29. Lesser MP (2006) Oxidative stress in marine environments: Biochemistry and physiological ecology. Annu Rev Physiol 68:253-278

30. Liu C, Guttieri MJ, Waters BM, Eskridge KM, Baenziger PS (2019) Selection of bread wheat for low grain cadmium concentration at the seedling stage using hydroponics versus molecular markers. Crop Sci 59:945-956

Page $10 / 13$ 
31. Mather K, Jinks JL (1982) Biometrical Genetics. Springer US, Chapman and Hall, London

32. Milad SI, Wahba LE, Barakat MN (2011) Identification of RAPD and ISSR markers associated with flag leaf senescence under water-stressed conditions in wheat ('Triticum aestivum'l.). Aust J Crop Sci 5:337-343

33. Nei M (1978) Estimation of average heterozygosity and genetic distance from a small number of individuals. Genetics 89:583-590

34. Nordberg GF (2009) Historical perspectives on cadmium toxicology. Toxicol Appl Pharmacol 238:192-200

35. Oladzad-Abbasabadi A, Kumar A, Pirseyedi S, Salsman E, Dobrydina M, Poudel RS, AbuHammad WA, Chao S, Faris JD, Elias EM (2018) Identification and validation of a new source of low grain cadmium accumulation in durum wheat. G3 8, 923-932

36. Pozniak CJ, Clarke JM, Clarke FR (2012) Potential for detection of marker-trait associations in durum wheat using unbalanced, historical phenotypic datasets. Mol Breed 30:1537-1550

37. Rizvi A, Zaidi A, Ameen F, Ahmed B, AlKahtani MDF, Khan MS (2020) Heavy metal induced stress on wheat: phytotoxicity and microbiological management. RSC Adv 10:38379-38403

38. Rohlf F (2000) NTSYS 2.1: numerical taxonomic and multivariate analysis system. Exeter Software, New York

39. Shafiq S, Zeb Q, Ali A, Sajjad Y, Nazir R, Widemann E, Liu L (2019) Lead, cadmium and zinc phytotoxicity alter DNA methylation levels to confer heavy metal tolerance in wheat. Int J Mol Sci 20:4676

40. Singh BR, Gupta SK, Azaizeh H, Shilev S, Sudre D, Song WY, Martinoia E, Mench M (2011) Safety of food crops on land contaminated with trace elements. J Sci Food Agric 91:1349-1366

41. Stolt JP, Sneller FEC, Bryngelsson T, Lundborg T, Schat H (2003) Phytochelatin and cadmium accumulation in wheat. Environ Exp Bo 49:21-28

42. Sun PLF, Shands HL, Forsberg RA (1972) Inheritance of kernel weight in six spring wheat crosses 1.Crop Sci12:1-5

43. Tolcin AC (2009) Mineral resource of the month: Zinc. Earth 54:29-29

44. Uemoto Y, Sasaki S, Kojima T, Sugimoto Y, Watanabe T (2015) Impact of QTL minor allele frequency on genomic evaluation using real genotype data and simulated phenotypes in Japanese Black cattle. BMC Genetics 16

45. Williams JGK, Kubelik AR, Livak KJ, Rafalski JA, Tingey SV (1990) DNA polymorphisms amplified by arbitrary primers are useful as genetic markers. Nucleic Acids Res 18:6531-6535

46. Zaid I, Zheng X, Li X (2018) Breeding low-cadmium wheat: Progress and perspectives. Agron 8:249

47. Zhang X, Zhong T, Liu L, Ouyang X (2015) Impact of soil heavy metal pollution on food safety in china. PLOS ONE 10:e0135182

48. Zhou M, Sh Zheng R, Liu L, Lu Ch, Zhang L, Zhang L, Yant, Wu Y (2019) The genome-wide impact of cadmium on microRNA and mRNA expression in contrasting Cd responsive wheat genotypes. BMC Genom 20:1-63

49. Zietkiewicz E, Rafalski A, Labuda D (1994) Genome fingerprinting by simple sequence repeat (SSR)-anchored polymerase chain reaction amplification. Genomics 20:176-183

\section{Figures}



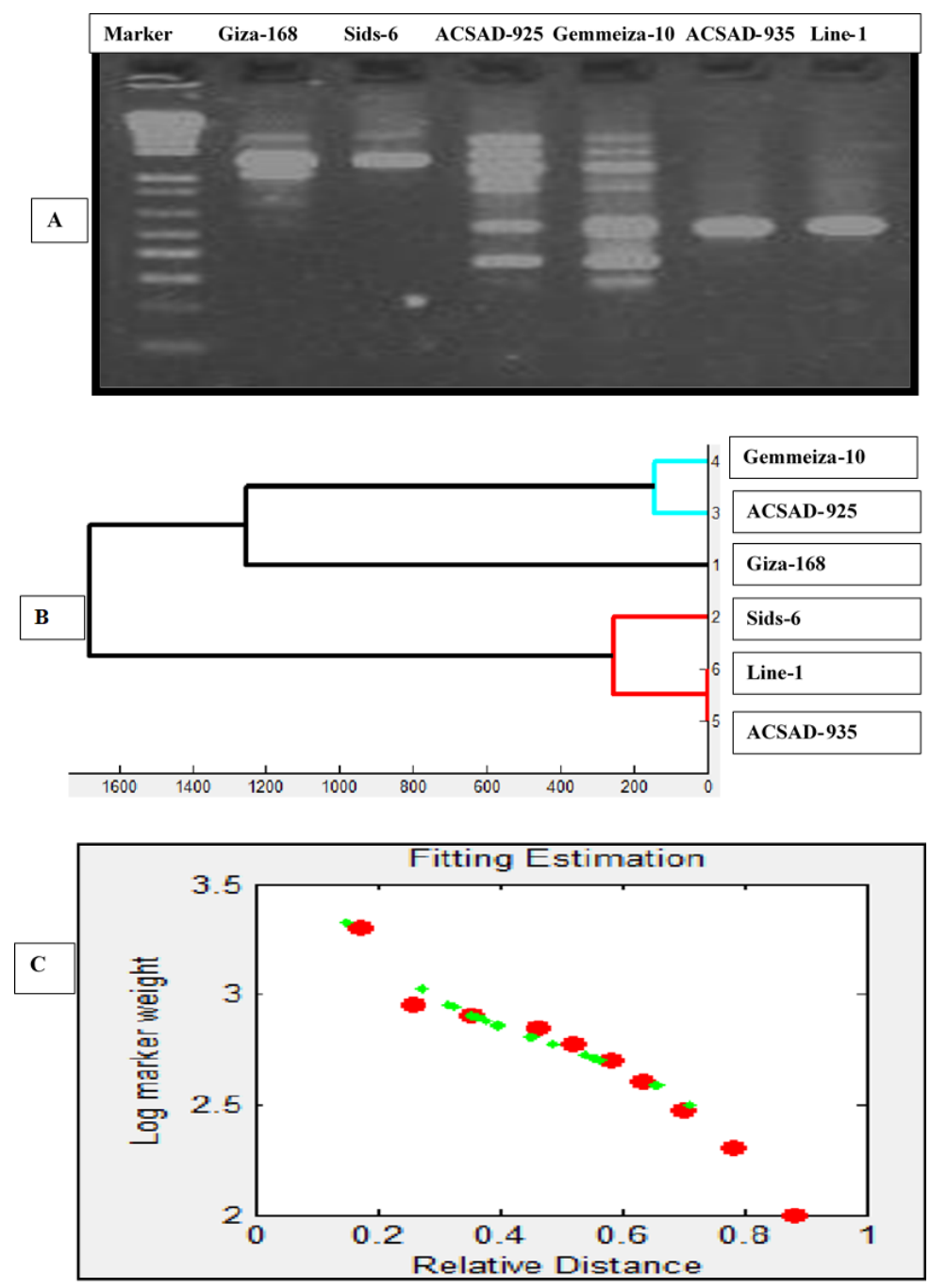

\section{Figure 1}

RAPD marker associated with polymorphisms among six wheat cultivars. A) RAPD amplification with triple-primers P3, P6 and P8. B) Dendrogram based on the algorithm of unweighted pair group method with arithmetic averages using RAPD results between in different wheat cultivars. C) Testing the accuracy of Triple-RAPD dendrogram using the fitting method plotting. 

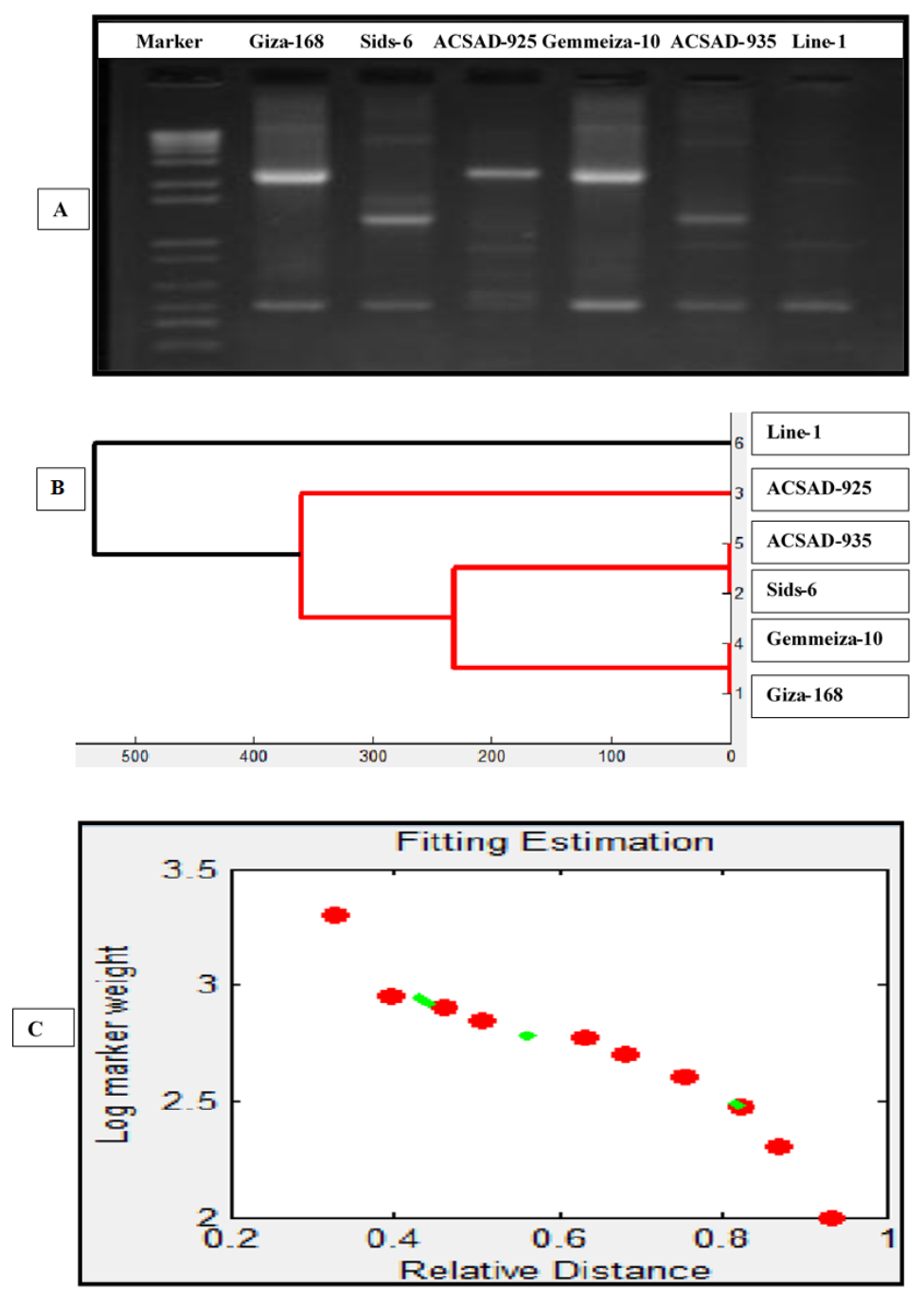

Figure 2

ISSR marker associated with polymorphisms among six wheat cultivars. A) PCR amplification with HB11 primer. B) Dendrogram based on the algorithm of unweighted pair group method with arithmetic averages using ISSR results between in different wheat cultivars in Egypt. C) Testing the accuracy of ISSR dendrogram using the fitting method plotting.

\section{Supplementary Files}

This is a list of supplementary files associated with this preprint. Click to download.

- Tables1.docx 